\title{
Paradoxes and paradigms: How can the social model of disability speak to international humanitarian assistance?
}

\author{
K. Layton \\ Graduate School of International Affairs, Department of International Relations, Research School of \\ Pacific and Asian Studies, The Australian National University, Acton, ACT 0200, Canberra, Australia.
}

In order for a theory to be dynamic and to remain useful, it must speak to other philosophies that operate with similar goals, so that it might translate its theory into practical policy. During the exercise of International Humanitarian Assistance (IHA) where people's lives are frequently at stake, and of disability rehabilitation where issues such as livelihoods, empowerment and development are being addressed, it is extremely important that the grand ideas advocated by theories are fully utilized by practitioners. Though the two philosophies of IHA and the Social Model of Disability come from quite diverse and disparate viewpoints, with IHA primarily working amid humanitarian emergencies in developing countries and the social model of disability examining the relations between individuals with disabilities and their societies, their language reveals that they converge on many issues. By analysing the discourses of both IHA and the social model of disability, important paradigms and paradoxes on both the theoretical and practical levels are uncovered. In this way each theory, each model, and each ideology can be refined and in turn, it can better the circumstances of the people who exist in the real-world situations the theories seek to inform.

\section{INTRODUCTION}

Articulating the relationship between international humanitarian assistance (IHA) and the social model of disability is central to understanding the paradoxes and paradigms that exist within and between the two theories. Though the two philosophies come from quite diverse and disparate viewpoints, with IHA primarily working amid humanitarian emergencies in developing countries and the social model of disability examining the relations between individuals with disabilities and their societies, their language reveals that they converge on many issues. A Critical Discourse Analysis of both IHA and the social model demonstrates a number of paradoxes that exist within them on two levels: the theoretical and the practical. A key theoretical paradox central to both theories is represented by the language of 'empowerment' and 'community'. Given the centrality of these two ideas, a better understanding of this paradox would benefit both IHA and the social model, and interaction between the two. Likewise, there exist a clear set of compatible assumptions, concepts, values, and practices that constitute a way of viewing reality for both theories. The way in which IHA and the social model operate within their similar paradigms elucidates the potential for positive engagement between the two. Ultimately, illuminating the analogous paradigms and the theoretical and practical tensions in one can help shed light on the paradigms and paradoxes inherent in the other.

For the purposes of this paper, the ongoing Palestinian/Israeli conflict will be examined in order to discover how the social model of disability can speak to IHA in order to further its work with conflict-related disability. After critically analysing the discourse of both IHA and the social model to discover the true extent of the theoretical and practical paradoxes within and between them, the practice of community-based rehabilitation (CBR) in Palestine will be used to further demonstrate the tangible effect that this discourse has on 'in the field' IHA work. This case study highlights that, in operational terms, the social model of disability has much to offer IHA practitioners in terms of presenting them with a framework through which to address the needs of disabled people during times of conflict and emergency. CBR in Palestine is thus a useful context to use in order to establish how the social model of disability can speak to IHA.

\section{CRITICAL DISCOURSE ANALYSIS}

Critical Discourse Analysis (CDA) is a way of approaching the interaction between rhetoric, politics, society and identity, that can facilitate the exploration of the way in which institutions and individuals communicate through written texts and 
verbal interactions (Lupton 1995). A basic definition of discourse analysis is provided by Wetherell, Taylor \& Yates (2001), who describe it as:

...the study of talk and texts. It is a set of methods and theories for investigating language in use and language in social contexts. Discourse research offers routes into the study of meanings, a way of investigating the back-and-forth dialogues which constitute social action, along with the patterns of signification and representation which constitute culture (2001: i).

CDA investigates language not as a mental, but rather as a social phenomenon. It primarily studies the way social discrimination, manipulation, inequality, power and control, are enacted, reproduced and resisted by text and talk in the social and political context (van Dijk 1993).

Wodak and Meyer (2001: 16) explain that CDA sees itself as a hermeneutic process; 'Compared to the (causal) explanations of the natural sciences, hermeneutics can be understood as the method of grasping and producing meaning relations.' CDA assumes that all discourses are historical and can therefore only be understood with reference to their context. Thus it refers to extra linguistic factors such as culture, society and ideology. They continue by linking the idea of context to CDA's 'interdisciplinary claim and its description of the object of investigation from widely differing perspectives' (2001: 16), and argue that CDA, when compared to other linguistic methods of text analysis, seems closest to sociological and sociopsychological perspectives. I suggest further development of this point and argue that the emphasis CDA puts on explaining relations of power through language, makes it a particularly useful tool with which to understand how the discourse of IHA and the social model of disability influences the way in which the two theories can speak to each other.

\section{LOCATING DISABILITY IN IHA: WHY DOES IT MATTER?}

The United Nations' International Year of Disabled Persons (UNIYDP) was held in 1981 with the goal of obtaining 'full participation and equality' for all disabled people. General Assembly resolution $36 / 77$ stated that the member states were 'deeply concerned that no less than five hundred million persons are estimated to suffer from disability of one form or another, of whom four hundred million are estimated to be in developing countries.' Later The International Decade of Disabled Persons was held between 1983 and 1993. Today the UN estimates that there are more than 650 million people and 2 billion directly affected by disability, if family members are included. This represents approximately one third of the world's population.

The 2007 World Bank Guidance Note on Incorporating Disability-Inclusive Development into Bank-Supported Projects recognizes that the majority of people with disabilities live in developing countries, those countries in which IHA practitioners most often find themselves. Their increasing numbers are the result of conflict, malnutrition, diseases including HIV/AIDS, aging and natural disasters.

\section{CONFLICT IS ALWAYS INCLUSIVE}

In any society, the vulnerable members are groups such as the socially, physically or mentally disabled, women and children. Emergencies such as natural disasters or conflict situations exacerbate the vulnerability of these groups. Disabled people (this group includes the elderly) are overwhelmingly represented in refugee communities (Pankhurst 1984) and are disproportionately affected by disasters and conflict. Conflicts and natural disasters are both direct and indirect causes of disabilities: directly through physical injuries, and indirectly thorough lack of quality medical care and disruption of health care services and infrastructure. Furthermore, disabled people and their relations may encounter additional problems due to the loss of mobility aids, difficulty in accessing information, food, water and/or sanitation sources. For IHA practitioners, disable people are most certainly a vulnerable group that requires targeting. IHA practitioners must therefore consider the implications (both long and short term) of their actions.

Article 11 of the UN Convention on the Rights of Persons with Disabilities says that:

States Parties [sic] shall take, in accordance with their obligations under international law, including international humanitarian law and international human rights law, all necessary measures to ensure the protection and safety of persons with disabilities in situations of risk, including situations of armed conflict, 
humanitarian emergencies and the occurrence of natural disasters.

Following this, disabled people must be considered a target group across all assistance processes including detection and identification, assessment and planning, delivery of support programs, monitoring, review and evaluation. Article 11 means that, in the field, aid organizations must pro-actively seek out and engage with disabled people, their family members and care-givers in order to ensure they are registered and provided with support. At home, donor agencies must include within their funding strategies designs that specifically recognize disabled people's needs. This must include both supporting disabled people in terms of them being aid-recipients (for example, reconstruction projects must ensure that there are appropriately designed shelters and camps) and also including them as active participants in the wider community's response to the crisis. Ultimately, it is imperative that disabled people do not get lost in the chaos of emergency.

\section{THE SOCIAL MODEL OF DISABILITY}

Peter Coleridge, in his book, Disability, Liberation and Development (1993), explains the social model of disability as follows:

The social model of disability begins from the point that integration is ultimately about removing barriers, not 'normalisation', cure or care. Rehabilitation within a comprehensive social framework is about the removal of barriers at the individual level; it is also about the removal of physical and attitudinal barriers in society at large (Coleridge 1993: 73).

The social model is an approach and an attitude to disability, whereas the 'individual model' is more prescriptive. The individual model includes both the charitable and the medical models of disability in which the disabled person is presented as the problem. Within this model there is no perception of the need to change society to better the position and circumstances of disabled people. The individual model favours institutions and promotes the segregation of disabled people. It is important to note that the social model (as practiced in its most current, more moderate form ${ }^{1}$ ) does not negate the need for appropriate medical and rehabilitative care, what it does do is seek to adapt the system to the person, rather than force the person to adapt to the system. It has thus become an emancipatory force for many disabled people worldwide.

In the Oxfam publication, Disabled Children in a Society at War, Hastie (1997) further explains that the social model sees beyond the specific impairment of the individual and in doing so, requires disabled people to define the services they require, and take a prominent and active role in project design, decision-making and project management. The social model recognises that disability is not just a medical problem but rather, that the actual 'disabling' of the individual person is the result of a combination of architectural, institutional and prejudicial barriers. It stresses the empowerment of disabled people and encourages them to take control of their futures by speaking up against inherently unfair and inaccessible societies, and to work to locate themselves within projects that relate to disabled people in order to make sure their voices are heard.

\section{COMMUNITY-BASED REHABILITATION (CBR)}

CBR combines the positive aspects of both the medical and social models of disability by providing physical rehabilitation and continued medical care whilst promoting empowerment and social inclusion. It returns power to both the disabled individual and the community by including them in the process of rehabilitation and management of the impairment. Furthermore, CBR facilitates cooperation between the disabled person, their family, the wider community and IHA practitioners, requiring positive engagement and understanding between all actors if it is to work successfully.

CBR is particularly compatible with the ideologies of most NGOs (such as ICRC, Oxfam and World Vision) as it focuses of the obtention and promotion of human rights, equality and emancipation, and encourages inclusion and social integration. Its desire to create equal opportunities for employment and the way it utilizes means that are already present in the community, makes good use of scarce resources. Local knowledge is respected and a high

\footnotetext{
${ }^{1}$ For a discussion of the more radical, 'UK version' of the social model see Shakespeare and Watson 2002 as well as Tregaskis 2002 .
} 
value is placed on indigenous knowledge and practices, 'the key being to 'unlock' existing expertise within communities enabling them to develop their own community process that builds on and validates existing indigenous knowledge and information systems, while facilitating access to relevant information and ideas from outside the community' (World Bank Guidance Note 2007).

\section{THE PARADOX ${ }^{2}$ OF 'EMPOWERMENT' AND 'COMMUNITY'}

The concept of empowerment is central to the way the social model of disability is used by IHA as a theoretical framework for aid projects. It logically features in CBR just as prominently. As WHO's Disability and Rehabilitation Team state at the outset of its explanation of CBR, 'CBR is a multi-sectoral approach and has 5 major components: health, education, livelihood, social and empowerment'. However, as recognised by many scholars (Riger 1993; Schloss, Alper and Jayne 1993; Kendall, Buys and Larner 2000) the very idea of 'empowerment' is a paradox. The tensions that surround the way empowerment is conceptualised within the social model can speak to IHA. They are the same tensions that exist for any emergency assistance program seeking to create a solid 'empowered' foundation for later development. Arguing that giving people back their agency, or 'empowering' them, after a time of acute crisis raises similar issues to those when discussing empowering disabled people who are (or at least are seen to be) marginalised.

Empowerment relies on the assumption that there is pre-existent 'power' available to be transferred between groups or people. In this sense power is a relational construct that rather than being created or destroyed, simply exchanges hands. During a humanitarian emergency there may not be any power to transfer to the disabled population, or similarly, there may be so little power available to share that giving power to one vulnerable group necessarily subtracts power from another. Manipulating power in this way causes unequal relationships (Schloss, Alper and Jayne 1993) as well as conflict between actors, hence causing a situation that directly contradicts the tenets of the social model, CBR, and IHA. These models all champion the importance of equal relationships. Furthermore, this notion of the transferring of power

\footnotetext{
${ }^{2}$ See Kendall, Buys and Larne 2000 for the origins of this idea.
}

runs the risk of promoting an 'expert/client' situation. In the context of CBR, 'the idea that power can be taken by a rehabilitation worker and given to a client immediately suggests that power lies firmly with the worker' (Kendall, Buys and Larner 2000: 437). In IHA, the idea of an aid agency (who is almost always the outsider in any humanitarian emergency) donating its power to a vulnerable group, particularly at the risk of upsetting an already fragile balance of power between groups, is unsettling and raises questions about power, control and what type of assistance is most appropriate.

Riger asserts that 'finding one's voice, controlling one's resources and becoming empowered may reduce the interdependence that produces a strong sense of community' (Riger 1993: 278). She asks if the empowerment of vulnerable groups really brings about a greater sense of community or whether it in fact promotes certain groups at the expense of others, therefore increasing competitiveness and lack of cohesion. She recognises that pure Western-liberal philosophy,such as that which so often informs IHA, emphasises individual rights over community rights (Riger 1993). This obviously runs counter to the focus on social and community participation inherent in the way IHA actors practice the social model of disability. When speaking to IHA it is important to note, as do Thomas \& Thomas (1999) that 'in many developing countries, 'individual rights' as expressed in industrialised nations, do not exist. Traditionally in these countries, an individual is born in a kinship group, with a network of relationships that involve mutual obligations with regard to religious and economic factors. They warn that IHA practitioners must pay careful consideration to cultural factors when implementing programs like CBR through the social model lens because 'the process of 'empowerment' of an individual in this society is more complex, irrespective of whether he is a disabled person or otherwise."

Empowerment and power relations can also be observed from a gender perspective whereby traditionally masculine notions of power, mastery and control are used to the detriment of normatively feminine ideals of cooperation, and community. However empowerment may require women to take control of their lives in a society that does not fully accept such masculine behaviour. Thus, the discourse and construct of empowerment tends to favour middle-class Western males. It thus has the potential to disempower women and, more specifically, through the framework of the social 
model and CBR, to disempower disabled women. Thomas \& Thomas (1999) are critical of the fact that 'even the women's organizations in developing countries consider these women as disabled first and as women only secondarily.'

From a practicality perspective, 'buzzwords' such as empowerment and community suffer from a semantic vagueness that results in difficulty using them appropriately in applied policy. However even a brief visit to the websites of agencies such as WHO, Save the Children, Oxfam and ICRC prove that these buzzwords are regularly espoused in IHA. Riger (1993) remarks that admirable goals such as empowerment and community inclusion may hinder the achievement of the more tangible but less glamorous goals, such as physical aids. Too much rhetoric and not enough action is particularly damaging during humanitarian emergencies when what ought to come to the fore is practical action rather than ideological 'buzzwords'. In these emergency situations many of the disabled are newly disable due to conflict-acquired injuries; they therefore predominantly require practical assistance. Kendall, Buys and Larner rightly acknowledge that 'misrepresentation of empowerment and community inclusion can lead to the provision of inadequate support services and the placement of excessive demands on family members who are already experiencing significant pressure' (2000: 438). They further comment that 'rehabilitation practices that are characterized by inadequate support and structure are disempowering and fail to acknowledge the individual's right to relinquish control' (2000: 438). Just like any person that IHA attempts to help, disabled people deserve both choice and expert assistance; these two ideas need not be mutually exclusive. Neglecting concrete assistance in favour of positive-sounding discourse also critically affects the way in which emergency relief can make the transition to longer-term development. This 'relief to development continuum' provides numerous challenges for IHA practitioners. Development demands a solid foundation from which to work, and therefore it is vital that IHA implement projects (such as CBR) appropriately and responsibly, using the right mix language and practical policy.

\section{MOVING BEYOND WORDS: HOW IHA \\ PRACTITIONERS ARE USING THE SOCIAL MODEL TO INFORM PALESTINIAN CBR PROJECTS}

The second Palestinian Intifada, Al-Aqsa, began on 28 September 2000 due to the Palestinian people's growing frustration with the lack of tangible progress in implementing the 1993 Oslo agreement. This Intifada was much more violent and resulted in many more deaths and injuries than the first (1987-1994) due to the use of tear gas and snipers firing live and rubber-coated metal bullets. According to records held by the Red Crescent Organization and the Palestinian Ministry of Health, $13.4 \%$ of the injuries were severe enough to have serious implications for disability and the need for long-term care and support (Halileh et al. 2002). The Palestinian Red Crescent reports 737 injuries in the West Bank and Gaza so far during 2008 and 32,569 deaths since the beginning of Al-Aqsa. Although armed conflict obviously has serious direct consequences on human lives in terms of death or injury, its effect on infrastructure and services can lead to indirect consequences, such as high numbers of disabled people, which are potentially more widespread and severe. For this reason the role of NGOs in providing health services, such as CBR is of the utmost importance.

There is solid history of rehabilitation and disability-related services in Palestine for aid agencies in the region to build on. Since the 1940s, they have primarily been carried out by local and international NGOs however until the 1970s they focused mainly on deafness and blindness (Eide, Harami and Greer 2005). In the 1980s, during the first Intifada, many NGOs started special programs for disabilities which included CBR projects. In 1994, the Palestinian National Authority took full responsibility for the health sector and rehabilitation and disabilities were given special support, especially in terms of institutional capacity building and staff development. In 2005, there were 23 NGOs, grouped into 5 regional subcommittees-Nablus, Jenin, Southern Region, Central Region and Gazathe main supporters being The Norwegian Association of the Disabled and Diakonia. The importance of CBR in transforming the lives of disabled people in Palestine cannot be underestimated. Continuous promotion of community awareness and activity on the issues affecting disabled people since at least the early 1980s, when the United Nations Relief and Works Agency (UNRWA) began its first CBR programs, has led to increased integration and acceptance. After the first Intifada an improved CBR, based on these early programs, was able to operate beyond the political spectrum and draw on a wider variety of sources for sustainable development which has led to wide acceptance of the social model and the importance of disability-rights (Ashtan 1997: 56). 


\section{CONCLUSION}

As Finkelstein (2001) asserts in his discussion of the social model:

Models are constructed so that an object can be looked at in different ways and under different conditions. Models are artificial and do not explain anything. Model airplanes, for example, are constructed to see how they might behave in a wind-tunnel. The model airplane will not explain the laws governing flight, although they might provide the insight from which laws of flight are inspired. A good model can enable us to see something which we do not understand because in the model it can be seen from different viewpoints (not available to us in reality) and it is this multidimensioned replica of reality that can trigger insights which we might not otherwise develop.

This statement about the utility of models can further be applied to theories and, I believe, this can help us to understand why looking at the way theories and models speak to each other is important. When theories interact and seek to inform each other, they open themselves up to critical evaluation from an outside source (the other theory). When IHA and the social model of disability engage, they approach each other from completely separate schools and yet their agreement on so many issues demonstrates their potential to positively influence each other, and help each develop into better and more complete theories.
By analysing the discourse of both IHA and the social model, important paradigms and paradoxes on both the theoretical and practical levels are uncovered. Using a discussion of the social modelbased CBR projects in Palestine, as operated by IHA practitioners, these paradigms and paradoxes are further illuminated. In addition to this, this case study highlights that, in operational terms, the social model of disability has much to offer IHA practitioners through providing a framework which addresses the needs of disabled people during humanitarian emergencies. It has been the aim of this study to demonstrate that in order for a theory to be dynamic and to remain useful it must speak to other theories which operate with similar goals. In this way each theory, each model, and each ideology can be bettered and in turn, can better the circumstances of the people who exist in the realworld situations they seek to inform.

\section{ACKNOWLEDGEMENTS}

This paper would not have been possible without Professor Raymond Apthorpe and Michele Acuto. Their International Humanitarian Assistance course at The Australian National University's Graduate School of International Affairs (GSIA) provided an inestimable and unequalled intellectual space in which to develop ideas such as the one proposed in this work. For their help and advice regarding the development of this essay, I am eternally grateful.

\section{REFERENCES}

Coleridge, P., 1993. Disability, Liberation and Development, Oxfam, London.

Eide, A. H., Harami, G., and Greer, C., 2005. A Community-Based Approach to Rehabilitation in Palestine and its Implications for Social Life, Human Rights and Democracy, Bridges, 1(2): 1-7.

Finkelstein, V., 2001. The Social Model of Disability Repossessed, Manchester Coalition of Disabled People, Available at: <http://www.leeds.ac.uk/disabilitystudies/archiveuk/finkelstein/soc\%20mod\%20repossessed .pdf> (accessed 10 June 2008).

Hastie, R., 1997. Disabled Children in a Society at War: A Casebook from Bosnia, Oxfam, London.
Kendall, E., Buys, N., and Larner, J., 2000. CommunityBased Service Delivery in Rehabilitation: The Promise and the Paradox, Disability \& Rehabilitation, 22(10): 435-445.

Lupton, D., 1995. D \& S forum: postmodernism and critical discourse analysis, Discourse and Society, 6(2): 301-304.

Palestinian Red Crescent Society, 2008. Total Number of Death \& Injuries - West Bank and Gaza, Available at: $<$ http://www.palestinercs.org/modules/cjaycontent/index. php?id=15> (accessed 20 May 2008) 
Pankhurst, A., 1984. Vulnerable Groups, Disasters, 8(3): 206-213.

Riger, S., 1993. What's wrong with empowerment?, American Journal of Community Psychology, 21(3): 279292.

Schloss, P. J., Alper, S., and Jayne, D., 1993. Selfdetermination for persons with disabilities: Choice, risk, and dignity, Exceptional Children, 60(3): 215-226.

Shakespeare, T. and Watson, N. 2002. The Social Model of Disability: An Outdated Ideology?, Research in Social Science and Disability, 2: 9-28.

Thomas, M. and Thomas, M. J., 1999. Editorial: Influence of Cultural Factors on Disability and Rehabilitation in Developing Countries, Asia Pacific Disability Rehabilitation Journal, 10(2).

Tregaskis, C., 2002. Social Model Theory: the story so far..., Disability \& Society, 17(4): 457-470.
United Nations Assembly, 1981. Resolution 36/77, Available at:

$<$ www.un.org/documents/ga/res/36/a36r077.htm> (Accessed 31 May 2008).

Van Dijk, T., 1993. Principles of Critical Discourse Analysis, Discourse \& Society, 4(2): 249-283.

Wetherell, M., Taylor, S., and Yates, S., 2001. Discourse Theory and Practice: A Reader, Sage Publications Ltd, London.

Wodak, R., and Meyer, M., 2001. Methods of Critical Discourse Analysis, Sage Publications Ltd, London.

World Bank Guidance Note, 2007. Incorporating Disability-Inclusive Development into Bank-Supported Projects, Available at:

$<$ http://go.worldbank.org/D9347MVP30> (Accessed 31 May 2008). 